\title{
Rapid detection of antibodies against cytomegalovirus induced immediate early and early antigens by an enzyme linked immunosorbent assay
}

\author{
MONICA MUSIANI, CRISTINA CARPI, MARIALUISA ZERBINI
}

From the Institute of Microbiology, University of Bologna Medical School, Ospedale S Orsola, 9 via Massarenti, 40138 Bologna, Italy

SUMMARY An enzyme linked immunosorbent assay (ELISA) for detecting antibodies against cytomegalovirus induced immediate early antigens and early antigens was developed using purified nuclear antigens and was compared with the indirect immunofluorescence test. The tests were comparable in their ability to dectect positive and negative sera, and antibody titres determined by both assays were similar. The use of ELISA for the detection of antibodies against cytomegalovirus induced immediate early and early antigens is advocated in diagnostic and research laboratories.

Human cytomegalovirus (CMV) can cause serious illnesses including congenital malformations, mononucleosis syndrome following blood transfusions, and serious, sometimes fatal, complications in organ allograft recipients. The wide range of CMV infections emphasises the need for diagnostic techniques capable of rapid and reliable detection of active CMV infection.

In cells infected by human CMV several antigens appear at varying intervals after infection. Before DNA viral replication CMV induces the appearance of immediate early ${ }^{1}$ and early ${ }^{2}$ antigens, which are present in the nuclei of infected cells $1 \mathrm{~h}$ and $24 \mathrm{~h}$ after infection respectively. About $72 \mathrm{~h}$ after infection, at the end of the CMV replication cycle, late antigens (LA) are demonstrable in the nucleus and cytoplasm of infected cells. ${ }^{3}$ It is also known that the immune response to these different antigens has a different incidence and importance. While high concentrations of antibodies to late antigens persist long after the recovery from a CMV active infection, the presence of antibodies against CMV induced immediate early and early antigens has been shown to be associated with an active CMV infection (primary or reactivated) in acutely ill patients, and antibody titres undergo a relatively rapid decrease after the disappearance of symptoms. ${ }^{4-6}$

Accepted for publication 17 October 1983
The presence of antibodies against CMV induced late antigens is normally shown by a complement fixation test ${ }^{7}$ or immunofluorescence technique; ${ }^{8}$ moreover, many enzyme linked immunosorbent assays have been developed to assess an immune state against CMV induced late antigens using, as a source of antigen, CMV infected cells fixed at the end of the viral replication cycle. ${ }^{9-11}$ The presence of antibodies against immediate early and early antigens, however, has always been shown only by an indirect immunofluorescence test, but the practical value of this assay is partially impaired by the presence of non-specific cytoplasmic IgG receptors in CMV infected cells ${ }^{12}$ or by the presence of aspecific antibodies to nuclear components in allograft recipients.

As an alternative method for detecting antibodies against immediate early and early antigens we suggest an enzyme linked immunosorbent assay (ELISA) with purified nuclear antigens, which besides good sensitivity and rapidity, can give an easier and more accurate interpretation of results.

\section{Material and methods}

\section{CELLS AND VIRUS}

Human embryo lung fibroblasts were grown in Eagle's minimum essential medium supplemented with $10 \%$ fetal calf serum and antibiotics and used between the 15th and 20th passage. The AD 169 strain of human CMV was used in all the experi- 
ments. The virus was propagated and harvested as previously described..$^{13}$

\section{SERUM SPECIMENS}

Two hundred and sixteen serum specimens were tested by the immunofluorescence technique and ELISA for the presence of antibodies against immediate early and early antigens. Thirty five sera from patients with post-transfusional CMV hepatitis and 81 sera from kidney transplant recipients with an active $\mathrm{CMV}$ infection were analysed. Ten sera from transplant recipients without signs of an active infection and 90 sera from healthy blood donors were also tested. Ten sera showing aspecific antinuclear antibodies by immunofluorescence were used as a control to reveal possible ELISA false positives.

\section{IMMUNOFLUORESCENCE}

Antibodies against CMV induced immediate early antigens were titrated by indirect immunofluorescence in CMV infected human embryo lung fibroblast cultures grown on coverslips, fixed $1 \mathrm{~h}$ after the adsorption period. Antibodies against early antigens were titrated using cells infected in the presence of $75 \mu \mathrm{g} / \mathrm{ml}$ of Ara $\mathrm{C}$ and used $72 \mathrm{~h}$ after infection.

\section{ELISA}

\section{Antigen preparation}

Immediate early antigens were prepared from CMV infected cultures $1 \mathrm{~h}$ after infection. Control antigens were simultaneously prepared from uninfected cultures. Cells were resuspended in hypotonic buffer ( $\mathrm{NaCl} 0.01 \mathrm{M}$, Tris- $\mathrm{HCl} 0.01 \mathrm{M}, \mathrm{pH} 7$, and $\mathrm{MgCl}_{2}$ $0.0015 \mathrm{M}$ ) and allowed to swell in an ice bath for 30 min. Cells were then disrupted in a homogeniser, and nuclei were separated from cellular debris by centrifugation at $1200 \mathrm{rpm}$ for $15 \mathrm{~min}$ through a cushion of $22.5 \%$ Ficoll 400 in isotonic buffer at $4^{\circ} \mathrm{C} .1^{14}$ After two washes in phosphate buffered saline the pellet of nuclei was solubilised with $1 \mathrm{ml}$ extraction buffer $/ 2 \times 10^{6}$ nuclei and sonically treated for $60 \mathrm{~s}$.

The extraction buffer was a slight modification of that used by Blanton and Tevethia's to solubilise CMV immediate early and early proteins $(0.02 \mathrm{M}$ Tris $\mathrm{HCl}, \mathrm{pH} 9,0.3 \mathrm{M} \mathrm{NaCl}, 10 \%$ glycerol, $1 \mathrm{mM}$ $\mathrm{CaCl}_{2}, 0.5 \mathrm{mM} \mathrm{MgCl}_{2}, 2 \mathrm{mM}$ EDTA, $1 \mathrm{mM}$ $\beta$-mercaptoethanol, and $300 \mu \mathrm{g} / \mathrm{ml}$ phenylmethylsulphonyl-fluoride). The sonicate was clarified at $6000 \mathrm{rpm}$ for $15 \mathrm{~min}$ at $4^{\circ} \mathrm{C}$, and the supernatant fluid was stored at $-20^{\circ} \mathrm{C}$.

Early antigens were extracted from cell cultures infected with CMV in the presence of $75 \mu \mathrm{g} / \mathrm{ml}$ of Ara $C, 72 \mathrm{~h}$ after infection, using the same method described above for immediate early antigen extraction.

The optimal dilution of antigens to be used in further serological testing was determined by block titration, using a positive reference serum with a high titre for immediate early and early antigens (FG 182: early antigens $>1 / 320$, immediate early antigens $>1 / 320$ ) and a normal serum. The dilution chosen corresponded to about four antigenic units.

Control antigens were used in each assay at the same concentrations used for early and immediate early antigens.

\section{Assay}

ELISA was performed by a method similar to that of Forghani et al. ${ }^{16}$ Briefly, polystyrene microtitre ELISA plates were labelled with $200 \mu \mathrm{l}$ of immediate early, early and respective control antigens diluted in $0.06 \mathrm{M}$ bicarbonate buffer $\mathrm{pH} 9.6$ for $24 \mathrm{~h}$ at $4^{\circ} \mathrm{C}$. The plates were then washed three times with phosphate buffered saline containing $0.05 \%$ Tween 20 (PBST) and the test sera diluted with PBST were added. The plates were then incubated at $37^{\circ} \mathrm{C}$ for $45 \mathrm{~min}$. Wells were washed three times with PBST and then incubated with alkaline phosphatase conjugated antiserum to human $\mathrm{IgG}$ for 30 min at $37^{\circ} \mathrm{C}$. After another three washes with PBST the substrate p-nitrophenyl phosphate in diethanolamine buffer ( $\mathrm{pH} 9.8$ ) was added. After $30 \mathrm{~min}$ at $37^{\circ} \mathrm{C}$ the reaction was stopped with $1.5 \mathrm{M} \mathrm{NaOH}$; the intensity of the reaction was measured with a spectrophotometer at $405 \mathrm{~nm}$.

Results were reported as the percentage of absorbance of the positive reference control serum.

\section{Results}

To establish a reliable baseline for the ELISA antibody assay in identifying sera containing antibodies to immediate early and early antigens, a total of 100 sera negative by immunofluorescence for immediate early antigens were tested using both immediate early and control antigens. The average value, expressed as the percentage of absorbance of the positive reference serum, was 3.75 with a standard deviation of 3.7. A value of about twice the negative control mean value (that is, 8) was chosen as the positive threshold for the ELISA detection of antibodies to immediate early antigens.

The same procedure was performed to assess the positive threshold for ELISA against early antigens. In 100 sera negative for antibodies to early antigens by immunofluorescence, the mean value found by the ELISA test was 4.8 with a standard deviation of $4 \cdot 3$. The value of 10 was chosen as the positive threshold for ELISA detection of antibodies to early 
antigens.

With these criteria, out of 100 sera negative by immunofluorescence for immediate early antigens 98 proved to be negative by ELISA while two were positive; of 100 sera negative by immunofluorescence for early antigens 96 proved true negative by ELISA while four had values above the positive threshold.

Of the 98 sera negative by immunofluorescence and ELISA for immediate early antigens, the average value was 3.41 with a standard deviation of 1.7 ; out of the 96 sera negative by immunofluorescence and ELISA for early antigens, the mean value was 4.25 with a standard deviation of $2 \cdot 7$.

A further 10 sera showing aspecific antinuclear antibodies by immunofluorescence were analysed by ELISA for immediate early and early antigens to exclude false positive reactions. These 10 sera proved negative for immediate early and early antigens by ELISA.

To assess the specificity of the ELISA procedure to test antibodies against immediate early and early antigens a total of 116 sera positive by immunofluorescence for immediate early and early antigens were evaluated by ELISA. Of 116 sera positive by immunofluorescence for immediate early antigens 113 proved positive by ELISA (that is, with a value $>8$ ) and three had values below the positive threshold. The distribution of values of sera positive by ELISA and immunofluorescence for immediate early antigens is shown in the figure (a).

Mean ELISA values (for both immediate early and early antigens) at different dilutions for sera positive by immunofluorescence are shown in the Table. The overall coefficient of correlation of the results with the 113 sera positive for immediate early antigens was $0 \cdot 83$.

The results obtained by ELISA compared with immunofluorescence in the evaluation of antibodies against early antigens showed that out of 116 sera with antibodies to early antigens determined by

Mean ELISA values at different dilutions for sera positive by immunofuorescence

\begin{tabular}{lll}
\hline & Dilution & Mean ELISA value \\
\hline Immediate early antigens & $1 / 5$ & $15 \cdot 3$ \\
& $1 / 10$ & $22 \cdot 10$ \\
& $1 / 20$ & $23 \cdot 76$ \\
$1 / 40$ & $37 \cdot 32$ \\
& $1 / 80$ & $73 \cdot 34$ \\
Early antigens & $1 / 160$ & $98 \cdot 83$ \\
& $1 / 5$ & $13 \cdot 5$ \\
& $1 / 10$ & 22.6 \\
& $1 / 20$ & $23 \cdot 2$ \\
& $1 / 40$ & $39 \cdot 42$ \\
& $1 / 80$ & $68 \cdot 13$ \\
\hline
\end{tabular}

immunofluorescence, three had values below the positive threshold $(<10)$. The distribution of values of the 113 sera positive for early antigens both by ELISA and immunofluorescence is shown in the figure (b).

The coefficient of correlation of the results obtained with the 113 sera positive for early antigens was $0 \cdot 81$.

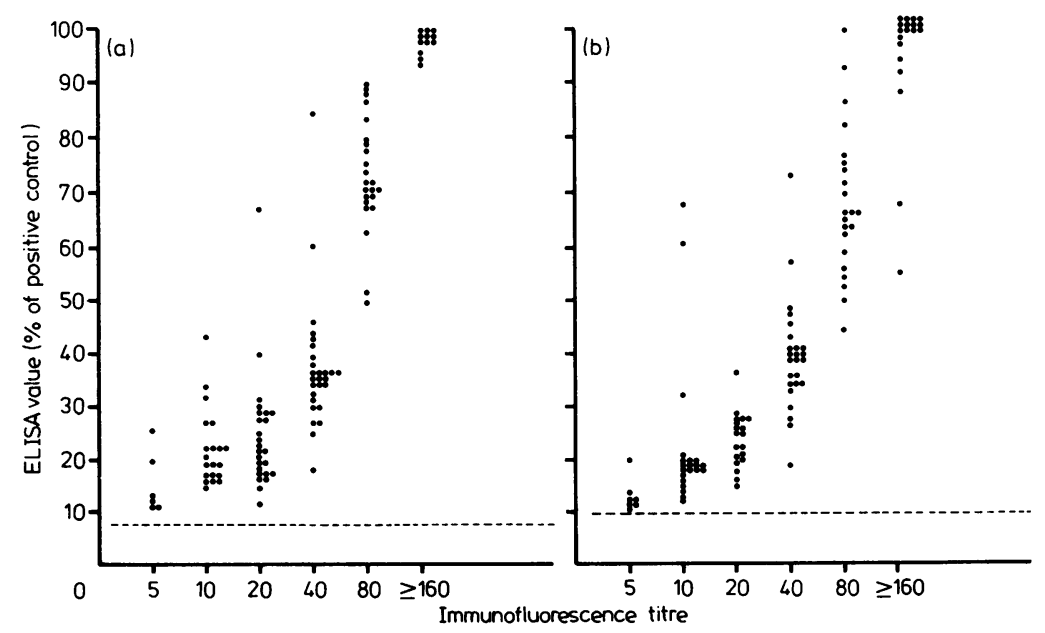

Correlation of concentrations of antibodies against immediate early antigens (a) and early antigens (b) measured by immunofuorescence and ELISA. Dotted horizontal lines represent the cut off point above which reactions are positive by ELISA. 


\section{Discussion}

We have developed an ELISA technique for examining the immune state for CMV induced nuclear immediate early and early antigens. As the presence of antibodies against these antigens has always been confirmed by indirect immunofluorescence we have compared ELISA and immunofluorescence.

The purification of nuclei and the extraction of nuclear proteins in preparing immediate early and early antigens for the ELISA procedure permitted an optimal correlation between ELISA and immunofluorescence and titres obtained by immunofluorescence strongly correlated with the results of ELISA tests. The coefficient of correlation between the immunofluorescence and ELISA techniques for the detection of antibodies to immediate early antigens was 0.83 and 0.81 for early antigens, indicating a close agreement between the two techniques. In addition, with our antigen preparation there was no interference from aspecific antinuclear antibody or non-specific cytoplasmic IgG receptors in CMV infected cells, allowing a more accurate and less subjective interpretation of the results. We found a few discrepancies between the two assays, which could be considered a difference of sensitivity of each assay.

Our findings suggest that the ELISA technique we describe fulfils the criteria of a practical, sensitive, and reliable assay for the detection of antibodies against CMV induced immediate early and early antigens. Previous studies ${ }^{4-6}$ have shown that the presence of antibodies against immediate early and early antigens in human sera is selectively associated with an active CMV infection while antibodies to CMV late antigens can last for long periods of time after recovery from an active infection. This implies that the ELISA procedure we have developed can make a rapid and easy serological diagnosis of an active CMV infection by testing only one serum sample, while with all other ELISA procedures able to detect antibodies to late antigens a diagnosis of a CMV active infection can be made only by testing at least two serum samples to appreciate a seroconversion.

The technical assistance of Miss Marinella Plazzi is gratefully acknowledged. We thank Mrs Valeria Zagnoli for her assistance in preparing the manuscript. The work was supported in part by CNR "Progetto Finalizzato Crescita Neoplastica" grant no 82.00436.96 and Progetto Finalizzato "Controllo delle Malattie da Infezione" grant no 82.02405.52.

\section{References}

${ }^{1}$ Michelson-Fiske S, Horodniceanu F, Guillon JC. Immediate early antigens in human cytomegalovirus infected cells. Nature 1977;270:615-7.

${ }^{2}$ The TH, Klein G, Langenhuysen MMAC. Antibody reaction to virus-specific early antigens (EA) in patients with cytomegalovirus (CMV) infection. Clin Exp Immunol 1974;16:1-12.

${ }^{3}$ Rapp F, Rasmussen LE, Benyesh-Melnick M. The immunofluorescent focus technique in studying the replication of cytomegalovirus. J Immunol 1963;91:709-19.

${ }^{4}$ The TH, Andersen HK, Spencer ES, Klein G. Antibodies against cytomegalovirus-induced early antigens (CMV-EA) in immunosuppressed renal-allograft recipients. Clin Exp Immunol 1977;28:502-5.

${ }^{5}$ Musiani M, Landini MP, Feletti C, La Placa M. Serum antibodies against cytomegalovirus-induced "early" and "immediate early" antigens and presence of viruria in renal transplant recipients. Microbiologica 1978;1:101-5.

- Gerna G, Cereda PM, Cattaneo E, Achilli G, Revello MG. Immunoglobulin $G$ to virus-specific early antigens in congenital, primary and reactivated human cytomegalovirus infections. Infect Immun 1978;22:833-41.

' Waner JL, Weller TH, Kevy SV. Patterns of cytomegaloviral complement-fixing antibody activity: a longitudinal study of blood donors. J Infect Dis 1973;127:538-43.

${ }^{8}$ Chiang WT, Wentworth BB, Alexander ER. The use of an immunofluorescence technique for the determination of antibodies to cytomegalovirus strains in human sera. J Immunol 1970;104:992-9.

9 Voller A, Bidwell DE. Enzyme-immunoassays for antibodies in measles, cytcmegalovirus infections and after rubella vaccination. Br J Exp Pathol 1976;57:243-8.

${ }^{10}$ Cappel R, De Cuyper F, De Brackeleer J. Rapid detection of IgG and IgM antibodies for cytomegalovirus by the enzyme linked immunosorbent assay (ELISA). Arch Virol 1978;58:253-8.

"Chia WK, Spence L. Quantitative determination of cytomegalovirus IgG antibody by enzyme-linked immunosorbent assay (ELISA). Can J Microbiol 1979;25:1082-6.

12 Rahman AA, Teschner M, Steki KK, Bandis H. Appearance of IgG (Fc) receptor(s) on cultured human fibroblasts infected with human cytomegalovirus. $J$ Immunol 1976;117:253-8.

${ }^{13}$ Landini MP, Musiani M, Zerbini M, Falcieri E, La Placa M. Inhibition of a complete replication cycle of human cytomegalovirus in actinomycin pre-treated cells. J Gen Virol 1979;42:423-8.

${ }^{14}$ Luka J, Siegert W, Klein G. Solubilization of the Epstein-Barr Virus-determined nuclear antigen and its characterisation as a DNA-binding protein. J Virol 1977;22:1-8.

is Blanton RA, Tevethia MJ. Immunoprecipitation of virus-specific immediate early and early polypeptides from cells lytically infected with human cytomegalovirus strain AD 169. Virology 1981;112:262-73.

${ }^{16}$ Forghani B, Schmidt NJ, Dennis J. Antibody assay for varicellazoster virus: comparison of enzyme immunoassay with neutralization, immune adherence hemagglutination, and complement fixation. J Clin Microbiol 1978;8:545-52.

Requests for reprints to: Dr Monica Musiani, Institute of Microbiology, University of Bologna Medical School, Ospedale S Orsola, 9 Via Massarenti, 40138 Bologna, Italy. 